\title{
Complex network analysis helps to identify impacts of the El Niño Southern Oscillation on moisture divergence in South America
}

\author{
Niklas Boers • Reik V. Donner • Bodo Bookhagen • \\ Jürgen Kurths
}

Received: 16 April 2014 / Accepted: 14 July 2014

(C) Springer-Verlag Berlin Heidelberg 2014

\begin{abstract}
We investigate the temporal evolution of moisture divergence and its spatial clustering properties over South America. Our analysis focuses on dependencies on the phase of the El Niño Southern Oscillation (ENSO). Moisture divergence is computed from daily reanalysis data of vertically integrated moisture flux provided by Modern-Era Retrospective Analysis for Research and Applications for the time period from 1979 to 2010. We use a sliding-window approach to construct a sequence of complex networks, each obtained from synchronization of events of strong positive (negative) moisture divergence, which we interpret as strong evapotranspiration (precipitation) events. We make the following three key observations: (1) Moisture divergence values over the Amazon rainforest are typically higher during positive ENSO periods (El Niño events). (2) The spatial coherence of strong positive (upwelling) events assumes a characteristic pattern of reduced coherence in this area during El Niño conditions. This influence of ENSO on moisture divergence and its spatial coherence is dominated by the El Niño events of
\end{abstract}

N. Boers $\cdot$ R. V. Donner $\cdot$ J. Kurths

Potsdam Institute for Climate Impact Research,

P. O. Box 6012 03, 14412 Potsdam, Brandenburg, Germany

N. Boers $(\square) \cdot$ J. Kurths

Department of Physics, Humboldt University, Newtonstr. 15, 12489 Berlin, Germany

e-mail: boers@pik-potsdam.de

B. Bookhagen

Department of Geography, University of California at Santa Barbara, Ellison Hall 1832, Santa Barbara, CA 93106, USA

J. Kurths

Institute for Complex Systems and Mathematical Biology, University of Aberdeen, Aberdeen AB24 3FX, UK
1982, 1987, and 1997. (3) The clustering characteristics of the obtained climate networks qualitatively agree with the spatial distribution of connected regions with simultaneous events (i.e., events that occur at the same time), but provide a more detailed view on the spatial organization of strong atmospheric upwelling events. Interestingly, no comparable results are found for negative extremes of moisture divergence (strong precipitation events).

Keywords Moisture divergence $\cdot$ Extreme events · South American climate $\cdot$ El Niño Southern Oscillation . Complex networks

\section{Introduction}

During the past decade, complex networks have become a powerful tool for the analysis of climate time series (Tsonis and Roebber 2004; Tsonis et al. 2007; Yamasaki et al. 2008; Donges et al. 2009b; Malik et al. 2012; Steinhaeuser et al. 2012; Berezin et al. 2012; Boers et al. 2013; Steinhaeuser and Tsonis 2014), resulting in the popular climate network $(\mathrm{CN})$ approach. Recent achievements particularly include novel insights into the global impact and spatiotemporal organization of the El Niño Southern Oscillation (ENSO) (Yamasaki et al. 2008; Tsonis and Swanson 2008), which have lead to a novel strategy for anticipating positive ENSO (El Niño) events (Ludescher et al. 2013) as well as discriminating between different types of positive and possibly also negative ENSO (La Niña) events (Radebach et al. 2013).

At a regional scale, the spatial patterns exhibited by various complex network measures based on the temporal synchronization between extreme rainfall events have been found to reveal the most important features of the South American 
Monsoon System (Boers et al. 2013). These include the main moisture pathways, their interplay with orography [orographic rainfall, (Bookhagen and Strecker 2008)], the main convergence zones, and areas with frequent thunderstorm development. Specifically, Boers et al. (2013) have documented that frequent occurrences of squall lines (Garreaud and Wallace 1997) and Mesoscale Convective System (Durkee et al. 2009; Durkee and Mote 2010) lead to high values of the local clustering coefficient in the resulting CNs. Notably, since the probability of two grid cells to exhibit a high degree of interdependence typically decays with their distance (Donges et al. 2009b; Radebach et al. 2013), high local clustering coefficients in CNs based on the synchronization of events indicate that extreme events in the corresponding region occur in a spatially coherent manner. Similar results have been obtained recently for the Indian summer monsoon (Malik et al. 2012), underlining the large potential of regional $\mathrm{CN}$ analysis.

In this work, we analyze strong positive and negative values (above the 90th percentile and below the 10th percentile) of the daily divergence of vertically integrated moisture flux. Positive moisture divergence, in simple terms, can be viewed as upward moisture transport from the surface to the atmosphere, for example caused by evapotranspiration; in contrast, negative moisture divergence corresponds to downward movement of moisture from the atmosphere to the surface in form of precipitation. We investigate the dependence of the associated spatial patterns on the ENSO phase, with a focus on the spatial coherence and large-scale organization of events. For this purpose, we use a sliding-window approach and construct $\mathrm{CNs}$ based on event synchronization [ES, cf. (Malik et al. 2010, 2012; Boers et al. 2013; Quiroga et al. 2002)] for time intervals of 365 days in steps of 60 days. We analyze the temporal evolution of local and global clustering coefficients of these CNs, and compare it to ENSO variability.

For comparison and in order to look at the resulting spatial patterns from a different viewpoint, we also compute the average size of connected regions of simultaneous events. Here, simultaneous means that events occur at the very same day, as opposed to synchronized, where we allow for a maximum delay of \pm 5 days between associated events. This approach provides a rather intuitive and direct way to analyze the spatial coherence of strong vertical moisture fluxes and adds quantitative information on the typical spatial extensions of simultaneous events in a given region. It can be understood as a more traditional approach to analyze spatial coherence, complementary to the $\mathrm{CN}$ approach.

\section{Data}

We employ daily data of vertically integrated moisture flux from NASA's Modern-Era Retrospective Analysis for
Research and Applications [MERRA, see (Rienecker et al. 2011)], with temporal coverage from 1979 to 2010 for the region between $15^{\circ} \mathrm{N}$ and $40^{\circ} \mathrm{S}$, and $30^{\circ} \mathrm{W}$ and $85^{\circ} \mathrm{W}$, at a latitudinal resolution of $1 / 2^{\circ}$ and longitudinal resolution of $2 / 3^{\circ}$.

Divergence of this flux was calculated using finite differences. Denoting vertically integrated atmospheric moisture content (i.e., precipitable water) by $A$, divergence of vertically integrated moisture flux by $M$, precipitation by $P$, and evapotranspiration by $E$, the water balance equation reads

$\partial_{t} A+M=E-P$.

We emphasize that $E$ and $P$ are never negative. A positive extreme of $M$ in a given grid cell can in principle be caused by two different effects: A sudden decrease of moisture inflow from neighboring grid cells, or an extreme event of $E$. In the former case, the neighboring grid cells cannot have a positive extreme event of $M$ at the same time step, while in the latter case extreme events should typically occur spatially homogeneously. Therefore, if positive extreme events of $M$ occur in a spatially homogeneous way, i.e., as part of large connected components of simultaneous positive extreme events, the former effect can be dismissed. As we will demonstrate in the course of this work (see Fig. 11 below), positive extreme events of $M$ occur in fact spatially homogeneously, which allows to interpret these events as extreme events of $E$. On the other hand, by the same rationale, negative extrema of $M$ typically lead to extreme events of $P$.

While spatial clustering of strong rainfall events has a straightforward interpretation in terms of thunderstorms and large convective systems and has been discussed elsewhere for South America (e.g., Boers et al. 2013), to our knowledge the spatial coherence of strong evapotranspiration events has not been discussed so far. This may be due to the fact that a climatological interpretation is not as simple as in the case of precipitation, since evapotranspiration is considered to be controlled by regional and local conditions. Here, we argue that factors influencing evapotranspiration rates, such as solar radiation, temperature, and wind, can indeed act coherently on rather large spatial scales and thus lead to interrelations of evapotranspiration time series at remote locations. We observe that evapotranspiration exhibits an event-like structure, i.e., short time periods during which values are much higher than during the remaining times (Fig. 1).

A particular focus of the following analysis will be on the Amazon Basin. In this area, evapotranspiration by dense vegetation cover and high biomass amounts-in combination with southwestward and westward propagating convective storm systems from the Atlantic Oceanyield an important contribution to overall positive moisture divergence (Lean and Warrilow 1989; Shukla et al. 1990; Eltahir and Bras 1993). 


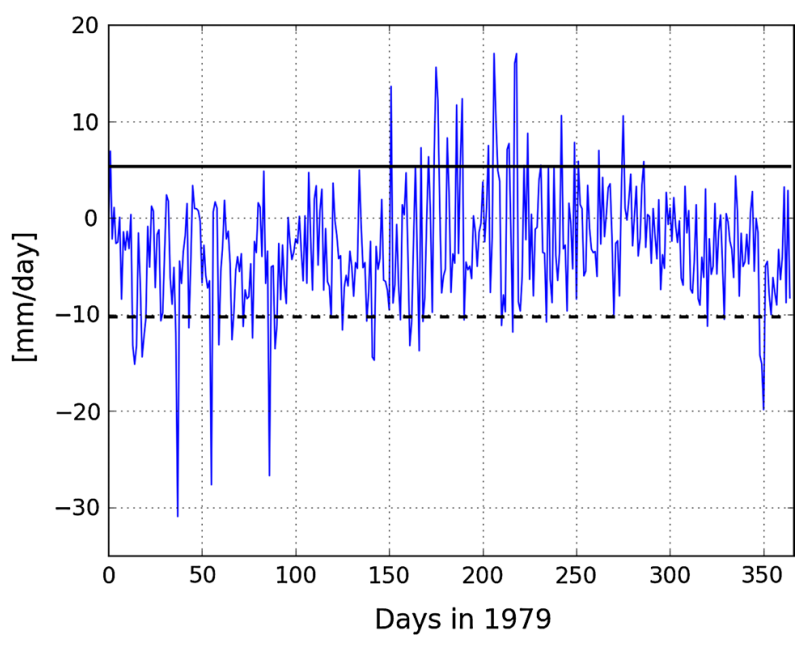

Fig. 1 Example of a daily time series of moisture divergence for 1979 at $5^{\circ} \mathrm{S}, 60^{\circ} \mathrm{W}$, and the corresponding thresholds at the 10th (dashed) and the 90th percentile (solid). Positive values indicate net evapotranspiration, while negative values indicate net precipitation

For the ENSO signal, we use the monthly multivariate ENSO index [MEI, ${ }^{1}$ (cf. Wolter and Timlin 1993, 1998)]. It is based on the six variables sea-level pressure, zonal and meridional surface wind components, sea and air surface temperature, and total cloud fraction. MEI is therefore considered a more reliable estimator of the ENSO state than indices like NINO 3.4 (based solely on sea surface temperatures) or SOI (based on sea-level pressure) (Rasmusson and Carpenter 1982; Trenberth 1997; Trenberth and Stepaniak 2001). Time intervals for which MEI is larger than +1 (smaller than -1) are considered to be warm, i.e., El Niño (cold, i.e., La Niña) episodes, while the remaining periods will be referred to as neutral.

\section{Methods}

\subsection{Climate network: generation}

In order to investigate the temporal evolution of the clustering characteristics of the obtained $\mathrm{CNs}$, we choose a sliding window approach. We construct $\mathrm{CNs}$ from time slices with a length of 365 days in steps of 60 days ( $\sim 2$ months), resulting in 195 time steps for the entire period between 1979 and 2010. Out of these, 38 fall into El Niño phases and 21 into La Niña phases. We first transform the data for each of these time slices and at each grid point into an evapotranspiration (precipitation) event series by considering those days as events for which $M$ is among the highest

\footnotetext{
${ }^{1}$ Retrieved from https://climatedataguide.ucar.edu/climate-data/multivariate-enso-index.
}

(lowest) $10 \%$ of all values for that location and time interval, resulting in 36 events for each time slice. We note that, since the percentiles are computed for each grid cell and time step, the corresponding event thresholds vary in space and time.

In order to construct a network from the obtained event series, we consider an event-based measure of similarity to decide whether or not two time series (i.e., $\mathrm{CN}$ nodes) are sufficiently similar to be connected by a $\mathrm{CN}$ link. For this purpose, we employ ES, defined as follows Malik et al. (2012), Boers et al. (2013), Quiroga et al. (2002): Suppose we have two event series $\left\{e_{i}^{\mu}\right\}_{1 \leq \mu \leq l}$ and $\left\{e_{j}^{\nu}\right\}_{1 \leq v \leq l}$ with $l$ events at grid points $i$ and $j$, where $e_{i}^{\mu}$ denotes the timing of the $\mu$ th event observed at grid point $i$. In our case, we consider $l=36$ events for all grid points and each time interval. In order to decide if two events $e_{i}^{\mu}$ and $e_{j}^{v}$ can be uniquely assigned to each other, we compute for $d_{i j}^{\mu, \nu}:=\left|e_{i}^{\mu}-e_{j}^{v}\right|$ (i.e., the waiting time between two events)

$\tau_{i j}^{\mu \nu}=\min \frac{\left\{d_{i i}^{\mu, \mu-1}, d_{i i}^{\mu, \mu+1}, d_{j j}^{\nu, \nu-1}, d_{j j}^{v, \nu+1}\right\}}{2}$.

To exclude unreasonably long delays between events at different locations, we introduce a maximum delay of $\tau_{\max }=5$ days. If $d_{i j}^{\mu, \nu} \leq \tau_{i j}^{\mu \nu}$ and $d_{i j}^{\mu, \nu}<\tau_{\max }$, we count this as synchronous events:

$S_{i j}^{\mu \nu}= \begin{cases}1 & \text { iff } \quad d_{i j}^{\mu, \nu} \leq \tau_{i j}^{\mu \nu} \quad \text { and } \quad d_{i j}^{\mu, \nu} \leq \tau_{\max }, \\ 0 & \text { else. }\end{cases}$

Note that if the respective threshold is exceeded for subsequent time steps, this will be considered as several distinct events. However, due to definition (2), at most one of these events will synchronize with the events identified at other grid points.

ES between $e_{i}$ and $e_{j}$ is then measured in terms of the normalized sum of all $S_{i j}^{\mu \nu}$ (for fixed $i$ and $j$ ):

$Q_{i j}:=\frac{\sum_{\mu \nu} S_{i j}^{\mu \nu}}{l}$.

Since $S_{i i}^{\mu v}=\delta_{\mu v}$ (i.e., $S_{i i}^{\mu \nu}=1$ iff $\mu=v$ and 0 otherwise) due to (2), we have $Q_{i i}=1$ by definition.

A CN is obtained by thresholding $Q$ at the 95th percentile, resulting in a link density of $5 \%$. The CN's adjacency matrix is thus given by

$A_{i j}=\Theta\left(Q_{i j}-\theta\right)-\delta_{i j}$,

where $\Theta$ is the Heaviside "function", $\theta=Q_{0.95}$ denotes the threshold on $Q$, and Kronecker's $\delta$ appears in order to exclude self loops. In this way, we construct $t=195 \mathrm{CNs}$ for time spans of 365 days, in steps of 60 days. We find that all event synchronization values that are represented by $\mathrm{CN}$ links through this procedure are significant ( $p$ value $<0.05$ ) with respect to a null model based on uniformly placing 36 
events (highest respectively lowest $10 \%$ ) in a time series of 365 days at random.

\subsection{Climate network: analysis}

By construction, clustering characteristics of synchronized evapotranspiration and precipitation events are encoded in the topology of the CNs constructed in the manner described above. Topological properties of $\mathrm{CNs}$ can be quantified by suitable $\mathrm{CN}$ measures. The first measure we consider here is the local clustering coefficient (LC):

$L C_{i}:=\frac{\sum_{j<k} A_{i j} A_{j k} A_{i k}}{\sum_{j<k} A_{i j} A_{i k}}$

$L C_{i}$ gives the relative frequency of network neighbors of $i$ that are themselves connected. Since the probability of a network link between two grid cells decays with their geographical distance (Donges et al. 2009b), a connected region with high local clustering coefficients will be a region of large spatial coherence: Strong events in regions of continuously high local clustering coefficients are expected to typically all occur close in time (within $\tau_{\max }=5$ days), while low local clustering coefficients indicate more erratic and spatially incoherent behavior. This is in agreement with an earlier study of spatial patterns of CNs from extreme precipitation (Boers et al. 2013).

The global clustering coefficient (GC) is defined as the arithmetic mean of local clustering coefficients taken over the entire network:

$G C:=\frac{1}{N} \sum_{i=1}^{N} \frac{\sum_{j<k} A_{i j} A_{j k} A_{i k}}{\sum_{j<k} A_{i j} A_{i k}}=\frac{1}{N} \sum_{i=1}^{N} L C_{i}$,

where $N$ is the number of nodes. Therefore, it gives an estimate of the overall tendency towards spatially coherent evapotranspiration or precipitation regimes.

\subsection{Connected regions of simultaneous extremes}

Complementarily to the $\mathrm{CN}$ approach, we also investigate the spatial patterns of the average size (measured as the number of grid cells) of spatially connected regions of simultaneous events (SC). Here, two grid cells are considered spatially connected if they are longitudinally, latitudinally, or diagonally adjacent in space. We first look for each day $\mu$ in a given time window (of length 365 days) for the $N_{\mu}$ spatially connected components $\left\{\mathcal{C}_{m}^{\mu}\right\}_{1 \leq m \leq N_{\mu}}$ of grid cells at which events occur at that day. Then, we assign to each grid cell the value of the size of the component it belongs to:

$S_{i}^{\mu}=\sum_{\left\{\mathcal{C}_{m}^{\mu}\right\}} \delta_{\mathcal{C}_{m}^{\mu}}(i)\left|\mathcal{C}_{m}^{\mu}\right|$, where $\left|\mathcal{C}_{m}^{\mu}\right|$ denotes the cardinality of $\mathcal{C}_{m}^{\mu}$ and $\delta_{\mathcal{C}_{m}^{\mu}}(i)=1$ if $i \in \mathcal{C}_{m}^{\mu}$ and $\delta_{\mathcal{C}_{m}^{\mu}}(i)=0$ otherwise. Finally, we average $S_{i}^{\mu}$ over all days $\mu$ for which $S_{i}^{\mu}>0$,

$S C_{i}=\frac{1}{t^{\prime}} \sum_{\left\{\mu \mid \mathcal{S}_{i}^{\mu} \neq 0\right\}} S_{i}^{\mu}$,

where in our case $t^{\prime}=36$ days. Since the actual size of horizontal grid cells depends on the latitudinal position, we correct the values of SC by weighting them with $\cos (\lambda)$, where $\lambda$ denotes the latitudinal angle ranging from $40^{\circ} \mathrm{S}$ to $15^{\circ} \mathrm{N}$.

\subsection{Pattern analysis}

The time evolution of CN's global clustering properties (GC) can be directly compared to ENSO variability. For LC, we obtain a vector of dimension $N$ (the number of grid points) for each time interval. But apart from the temporal evolution of the overall mean of this vector (i.e., GC), we are interested in a more detailed analysis of how the spatial patterns change during time evolution. For this purpose, we first compute Spearman's rank correlation coefficients between the ENSO signal and the time series of LC at each location.

Complementarily, we investigate the time evolution of spatial patterns of LC by means of pattern similarity analysis. For this purpose, we first compute the spatial ranks RLC of all LC values for each time interval: For each time step $\mu$, we have an $N$-dimensional vector $L C^{\mu}$, containing the values $L C_{i}^{\mu}$ of the local clustering coefficient for the $N$ geographical positions $i$. This array can be sorted with respect to these values. By "spatial ranks" $(R L C)$, we refer to the position $R L C_{i}^{\mu}$ (a number between 1 and $N$ ) of a given entry $L C_{i}^{\mu}$ in that sorted array. We then calculate the $L^{1}$-distance between the respective vectors $R L C^{\mu}$ and $R L C^{v}$ obtained for all pairs of time intervals $(\mu, v)$ :

$L^{\mu \nu}=\sum_{i=1}^{N}\left|R L C_{i}^{\mu}-R L C_{i}^{v}\right|$

with space indices $1 \leq i \leq N$ for the number of grid cells (i.e., $\mathrm{CN}$ nodes), $N=9,324$, and time indices $1 \leq \mu, v \leq t$ with $t=195$. The column- (or row-) wise mean,

$M L^{\mu}=\frac{1}{t} \sum_{\nu=1}^{t} L^{\mu \nu}$

of the symmetric distance matrix $\mathbf{L}=\left(L^{\mu v}\right)_{1 \leq \mu, v \leq t}$ provides information on the dissimilarity of a spatial pattern observed in a given time interval in comparison with the patterns attained during all other intervals. Low values indicate that the spatial patterns assume some characteristic structure at these times. Calculating $M L$ for all times results 
Fig. 2 Composites of mean daily moisture divergence $\mathrm{M}$ for warm (a), neutral (b), and cold (c) ENSO conditions, and difference of composites for warm and neutral ENSO conditions (d). Note the increased values in northern South America and along the equator during $\mathrm{El}$ Niño conditions
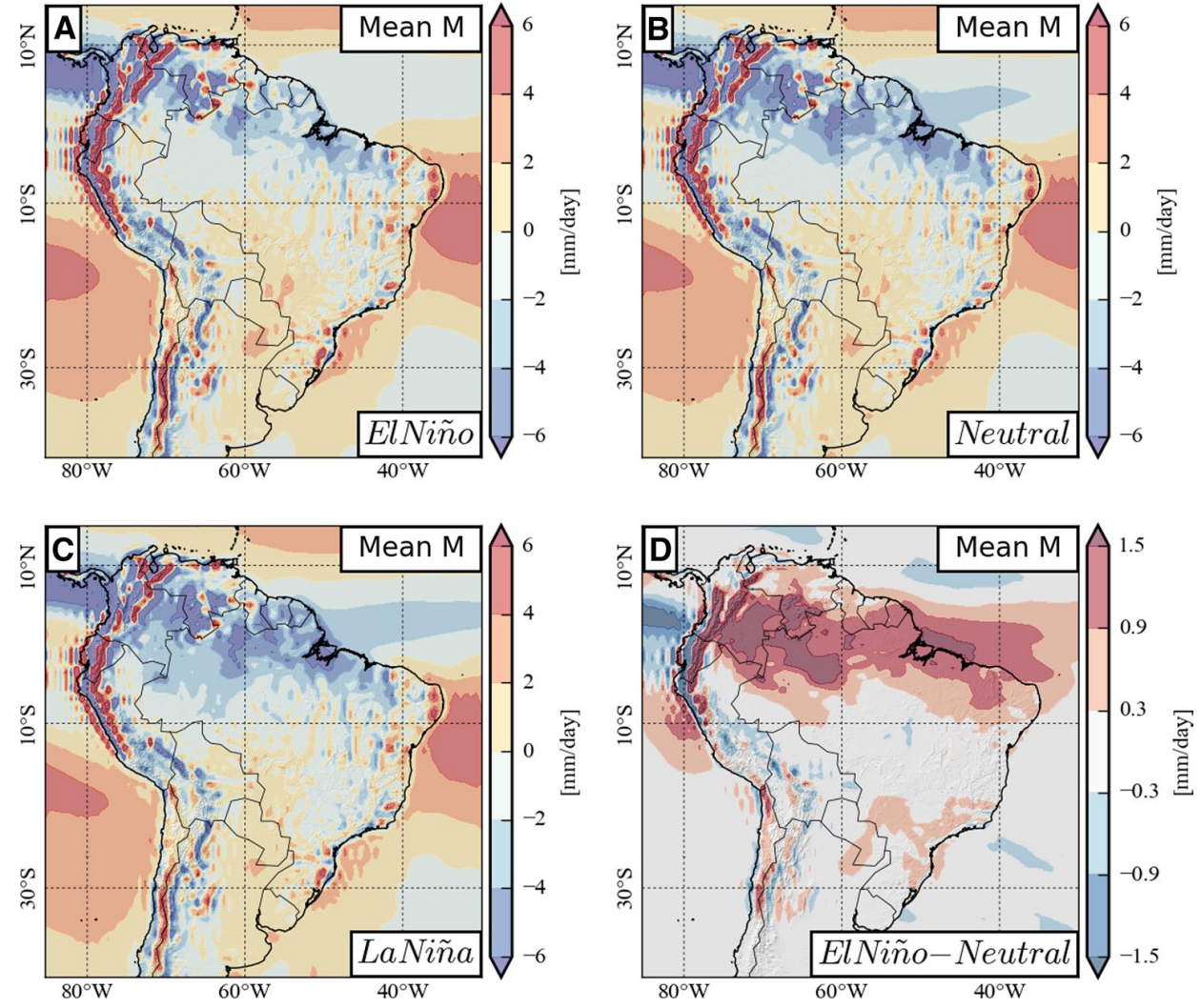

in another time series that can be compared to ENSO variability.

Finally, for LC and SC, we construct composites, i.e., we average the values at each location separately for warm (El Niño), neutral and cold (La Niña) stages of ENSO in order to obtain typical spatial patterns of these two measures for the three ENSO phases.

\section{Results}

\subsection{Spatial patterns of moisture divergence}

Regarding composites (i.e., spatial fields averaged over the respective time periods), we find that the strongest influence of ENSO on mean daily values of M (Fig. 2), as well as on the thresholds defining strong evapotranspiration (above the 90th percentile, Fig. 3) and precipitation (below the 10 th percentile, Fig. 4) events appears in a belt over the eastern and northern Amazon Basin and the adjacent coastal regions near the equator. Mean as well as strong evapotranspiration event thresholds increase in these regions during El Niño conditions, while strong precipitation event thresholds show the opposite behavior: values decrease over the tropical Atlantic Ocean and the entire Amazon Basin. The La Plata Basin exhibits higher 90th percentiles and lower (i.e., more pronounced negative) 10th percentiles during El Niño conditions, whereas average values are not markedly different in this area during the different ENSO phases.

For a more detailed quantification of the impact of ENSO on $M$, we employ Spearman's rank correlation coefficient (SR) to analyze the interdependence between ENSO based on the MEI and each local value of mean, 90th (strong evapotranspiration) and 10th (strong precipitation) percentiles of $M$. We find correlation values between +0.3 and +0.5 over the Amazon Basin and the tropical Atlantic Ocean close to the Brazilian coast for both mean values (Fig. 5a) and strong evapotranspiration events (Fig. 5b). In contrast, thresholds for strong precipitation events are negatively correlated with MEI (between -0.3 and -0.5 ) in this area (Fig. 5c).

Correlations between MEI and daily means of $\mathrm{M}$ are positive throughout eastern Brazil and negative in Uruguay and northeastern Argentina $\left(58^{\circ} \mathrm{W}, 32^{\circ} \mathrm{S}\right)$. In contrast, for strong evapotranspiration event thresholds, there are negative correlations in easternmost Brazil, while positive correlations reach from southeastern Brazil to northern Argentina, covering the entire La Plata Basin. Correlations between MEI and the 10th percentiles are positive with values between +0.3 and +0.5 in the southern La Plata basin.

In addition, we observe positive correlation values in the hyper-arid Atacama desert in northern Chile as well as on 
Fig. 3 Composites of 90th percentiles of moisture divergence $\mathrm{M}$ (corresponding to strong evapotranspiration events) for warm (a), neutral (b), and cold (c) ENSO conditions, and difference of composites for warm and neutral ENSO conditions (d). Note the increased values in northern South America and along the equator during $\mathrm{El}$ Niño conditions

Fig. 4 Composites of 10th percentiles of moisture divergence $\mathrm{M}$ (corresponding to strong precipitation events) for warm (a), neutral (b), and cold (c) ENSO conditions, and difference of composites for warm and neutral ENSO conditions (d). Note the decreased values in northern South America and along the equator during El Niño conditions
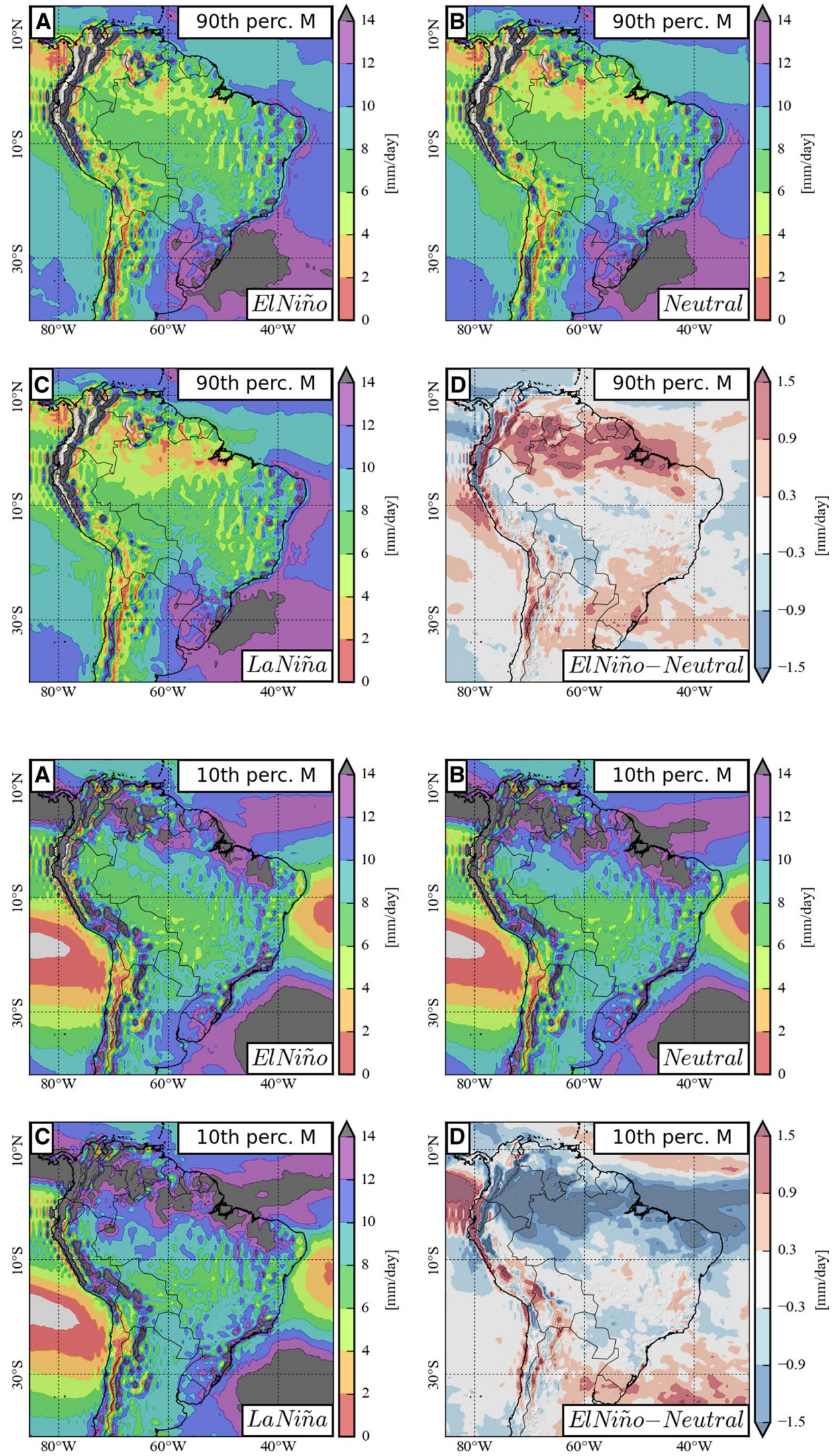

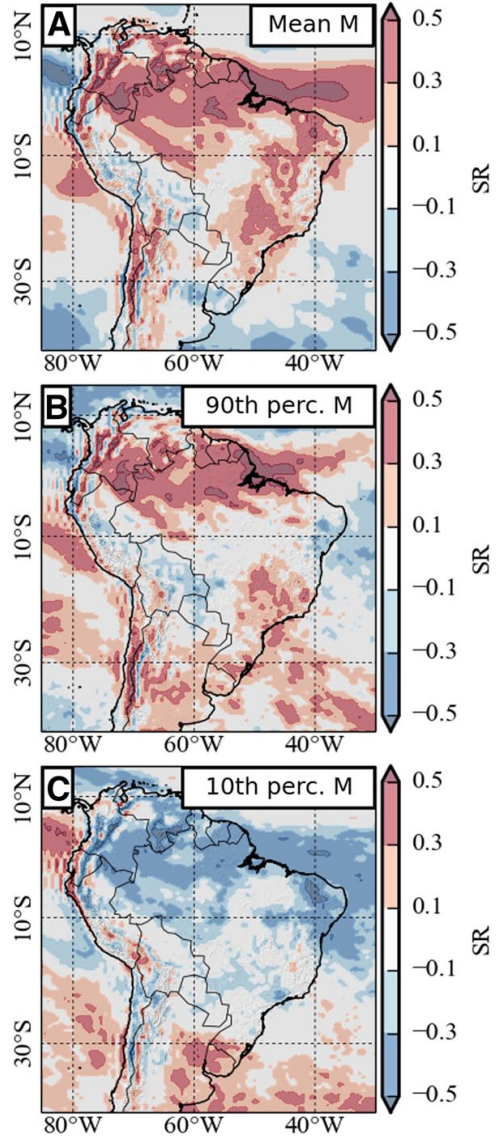

Fig. 5 Spearman's rank correlation coefficient (SR) between the ENSO index MEI and mean (a), 90th percentiles (b), and 10th percentiles (c) of moisture divergence M. Note in particular the positive correlations between mean and 90th percentiles of moisture divergence and MEI in northern South America, as well as the negative correlations in the same area for 10th percentiles

the adjacent Puna Plateau in northwestern Chile and southern Bolivia for both daily means and strong evapotranspiration event thresholds. In contrast, strong precipitation event thresholds are negatively correlated with ENSO in these regions.

\subsection{Clustering of extreme moisture divergence: time-dependence}

For strong evapotranspiration events, the distance matrix L (Fig. 6) obtained from the procedure described above exhibits reduced $L^{1}$-distance values for a variety of time intervals. Most notably, there appear two blocks in $\mathbf{L}$ which have shorter mean distances among themselves as compared to patterns obtained from other time intervals. These two blocks overlap between 1992 and 1998. The mean of $\mathbf{L}$ restricted to the time from 1979 to 1998 is $2.45 \times 10^{7}$ with standard deviation $0.32 \times 10^{7}$, and

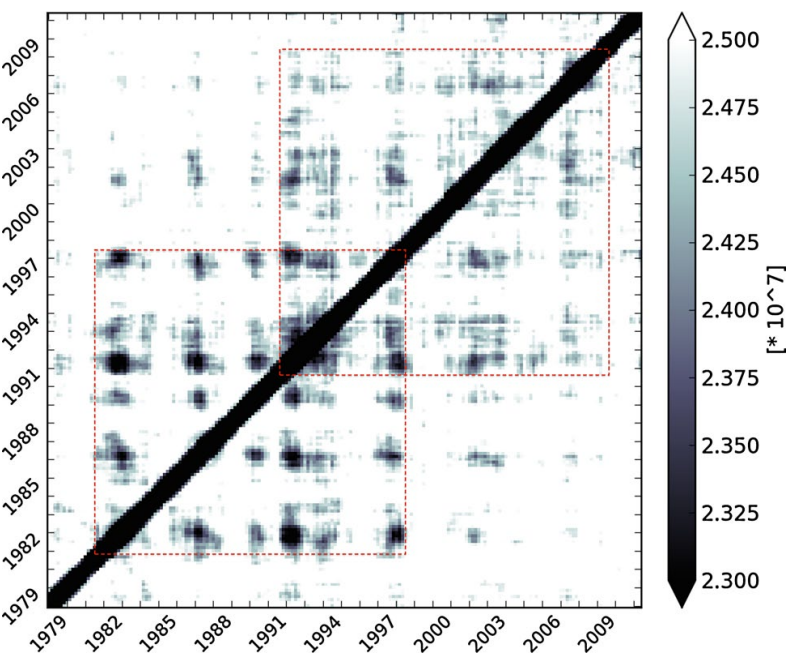

Fig. $6 L^{1}$-distance matrix $\mathbf{L}$ between the ranks of the local clustering coefficients (RLC) obtained for events above the 90th percentile (strong evapotranspiration events) for all time windows. Note the two time periods (1981-1998 and 1992-2009) with lower distances among themselves and higher distances to the respective other time period. The corresponding two blocks of $\mathbf{L}$ are indicated by dashed red lines

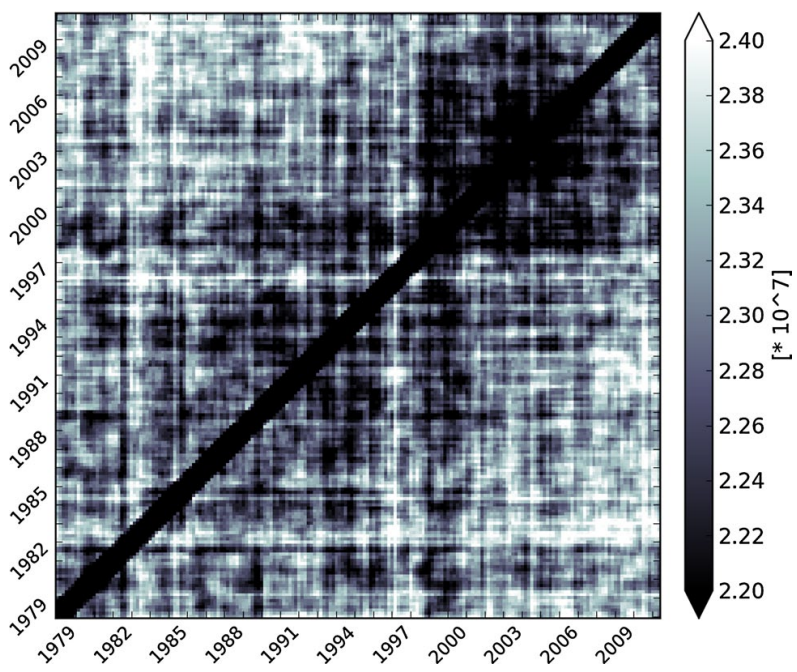

Fig. $7 L^{1}$-distance matrix $\mathbf{L}$ between the ranks of the local clustering coefficients (RLC) obtained for events below the 10th percentile (strong precipitation events) for all time windows

$2.44 \times 10^{7}$ with standard deviation $0.32 \times 10^{7}$ when restricted to the time from 1992 to 2012. For comparison, the mean of $\mathbf{L}$ between these two time periods (i.e., the mean of the block of $\mathbf{L}$ defined by $1998 \leq \mu \leq 2012$ and $1979 \leq v \leq 1991$ is $2.57 \times 10^{7}$ with standard deviation $0.06 \times 10^{7}$. For all times together, we obtain $2.50 \times 10^{7}$ for the mean of $\mathbf{L}$ and $0.25 \times 10^{7}$ for the standard deviation. For strong precipitation events, $\mathbf{L}$ does not show such a clear pattern (Fig. 7). 
Fig. 8 ENSO index MEI, $B$ row-wise mean (ML) of the $L^{1}$ -distance matrix $\mathbf{L}$ between the ranks of the local clustering coefficients (RLC), and $C$ time evolution of global clustering (GC) obtained for strong evapotranspiration events

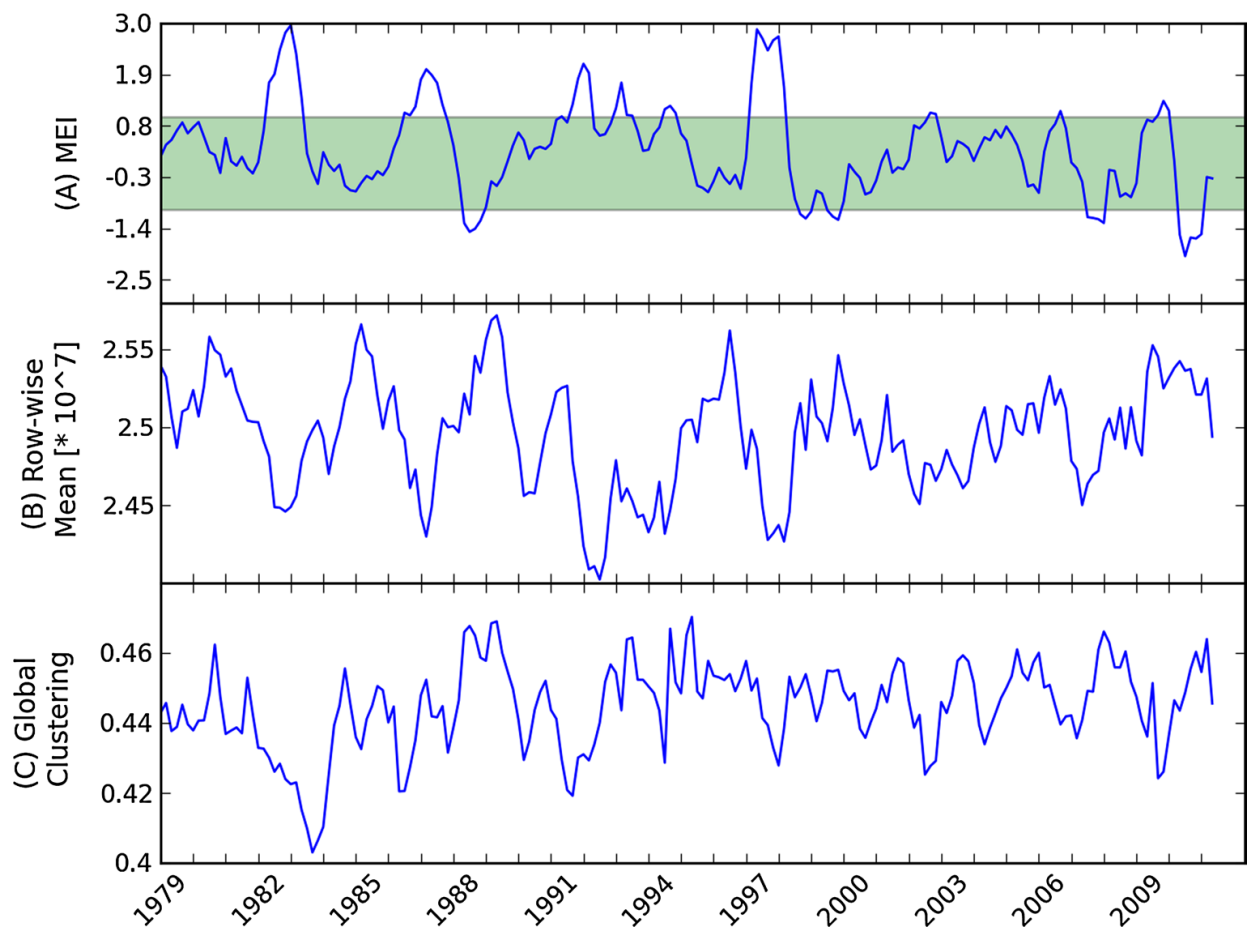

From 1979 to 2005, for strong evapotranspiration events the row-wise mean of $\mathbf{L}$ (ML, Fig. 8B) tends to have its minima at times of positive ENSO conditions. Here, minima correspond to the sequence of low values of $\mathbf{L}$ in Fig. 6 . The row-wise mean of $\mathbf{L}$ is anti-correlated with MEI (Fig. $8 \mathrm{~A}$ ) with $\mathrm{SR}(\mathrm{GC}, \mathrm{MEI})=-0.47$ ( $p$ value of the order of $10^{-12}$ ). In contrast, for strong precipitation events, the rowwise mean of $\mathbf{L}$ (Fig. 9B) does not show visual similarity to MEI, corresponding to low and non-significant correlation values.

The global clustering coefficient of the obtained CNs responds negatively to MEI, with $\mathrm{SR}(\mathrm{GC}, \mathrm{MEI})=-0.48$, for strong evapotranspiration events (Fig. 8C). The corresponding $p$ value, obtained from a two-sided $t$ test, is of the order of $10^{-13}$. For strong precipitation events, no visual interdependence between MEI and GC can be observed (Fig. 9C). In accordance, the correlation is much weaker in this case $(\mathrm{SR}(\mathrm{GC}, \mathrm{MEI})=-0.15$ with $p$ value $p=0.04)$.

Due to the weak interrelations between MEI and clustering properties obtained for strong precipitation events, we will focus on strong evapotranspiration events in the following sections.

\subsection{Spatial patterns of clustering of extreme evapotranspiration events}

Mean composites of LC (Fig. 10) show relatively high values over the Pacific Ocean between $10^{\circ} \mathrm{S}$ and $30^{\circ} \mathrm{S}$, over the tropical Atlantic Ocean and the adjacent coast of northeastern Brazil, and over most of subtropical South America for all three ENSO stages. Relatively low values can be seen over the central Andes and eastern central Brazil. Comparing the three different ENSO stages reveals that El Niño times are most notably characterized by decreased LC values over the entire Amazon Basin as compared to neutral and La Niña times.

For both positive and negative ENSO phases as well as neutral ENSO conditions, mean composites of the average size of connected regions of simultaneous events (SC, Fig. 11) show high values over the subtropical Atlantic Ocean and the adjacent southeastern South American continent. However, during La Niña times, these high values reach farther north towards the western Amazon Basin. In contrast, during El Niño episodes the values of SC decrease in these regions, in particular over the Amazon Basin north of $10^{\circ} \mathrm{S}$, when compared to the neutral ENSO stages.

\section{Discussion}

\subsection{Impacts of ENSO cycles on moisture divergence}

We observe that in the eastern and northern Amazon Basin, the distribution of $M$ is generally shifted towards higher values during El Niño conditions (Figs. 2, 3). Given the results reported by other studies (Hastenrath and Heller 1977; Ropelewski and Halpert 1987; Marengo et al. 2008; Bookhagen and Strecker 2010), we attribute this to negative 
Fig. 9 As Fig. 8 for strong precipitation events

Fig. 10 Composites of the local clustering coefficient (LC) based on strong evapotranspiration events for warm (a), neutral (b), and cold (c) ENSO conditions, and difference of composites for warm and neutral ENSO conditions $(\mathbf{d})$. Note the reduced values over the central and western Amazon Basin for El Niño conditions
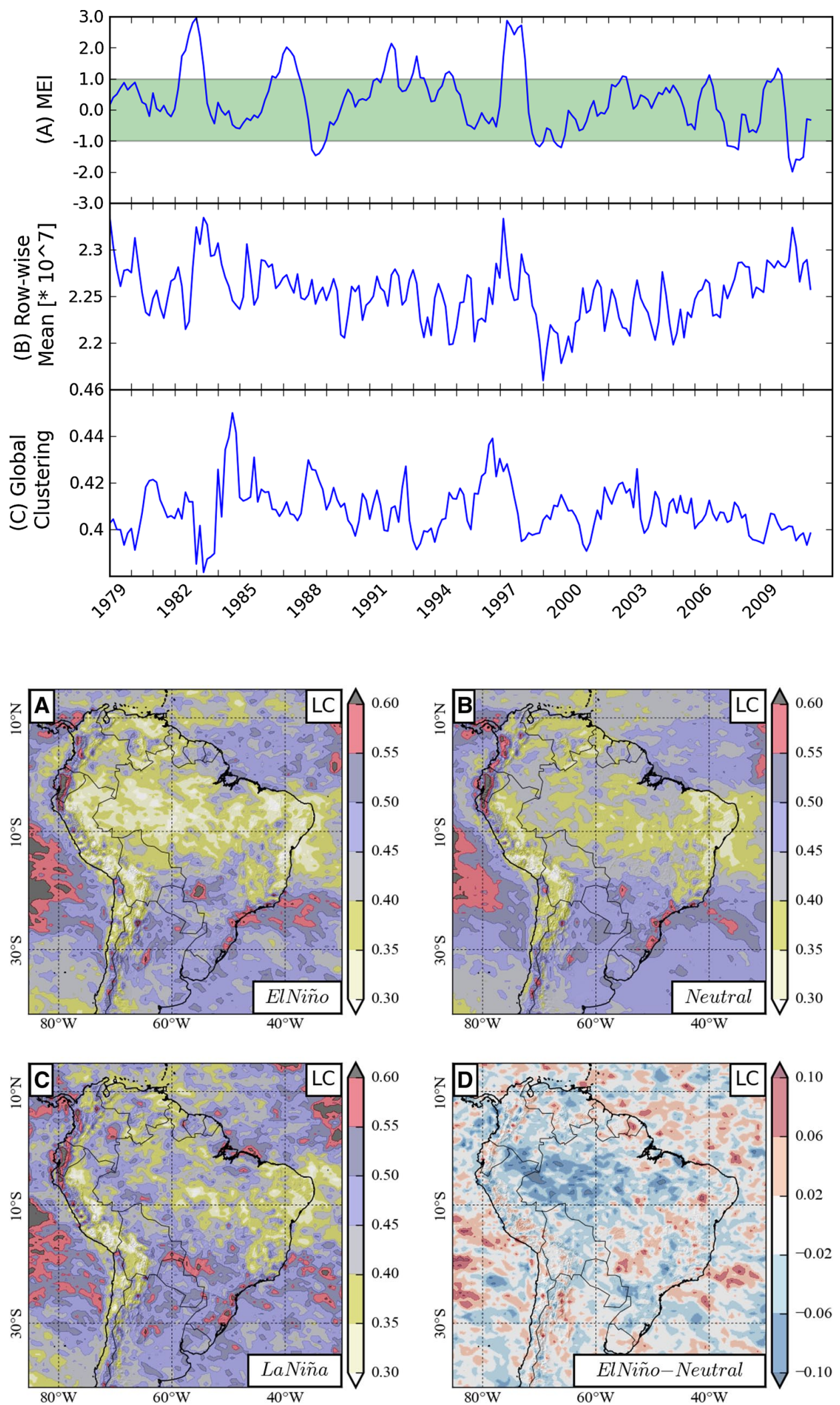
Fig. 11 As in Fig. 10 for the average size of connected components of simultaneous extremes (SC). Note the reduced values over the central and western Amazon Basin for El Niño conditions. Because the size of the horizontal grid cells varies depending on the latitudinal position, the values of SC have been corrected by weighting them with $\cos (\lambda)$, where $\lambda$ denotes the latitudinal angle
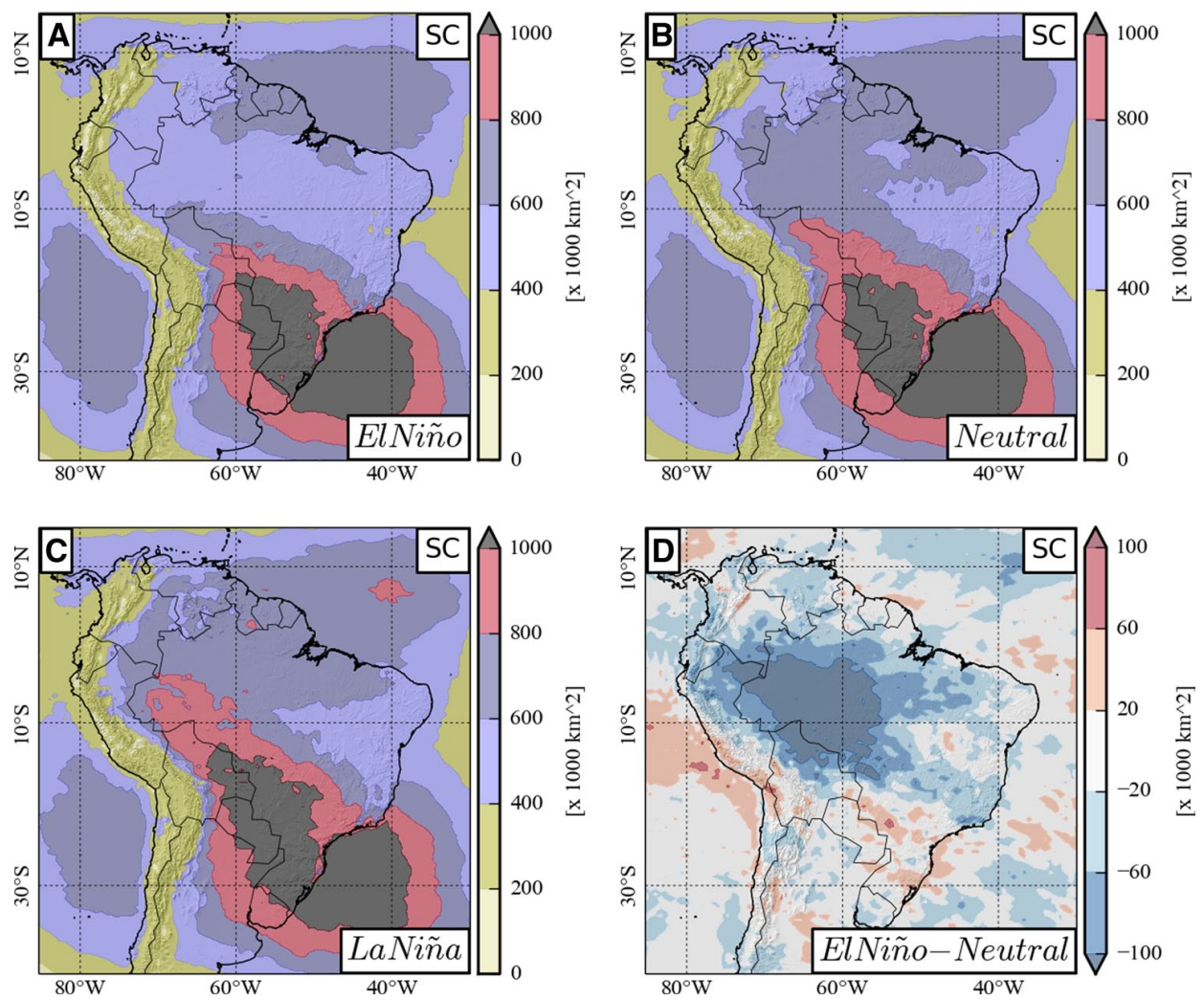

precipitation anomalies in the northern and eastern Amazon Basin during warm ENSO phases. In the La Plata Basin, positive as well as negative extremes of $M$ become more pronounced (Fig. 4), which indicates a general increase in variance (implying both stronger precipitation and evapotranspiration extremes) during El Niño events.

Negative correlation values between MEI and $M$ in the La Plata Basin for daily means as well as positive correlation values for the absolute values of 10th percentile thresholds are associated with positive precipitation anomalies in southeastern South America during El Niño events (Hastenrath and Heller 1977; Bookhagen and Strecker 2010; Cazes-Boezio et al. 2003). However, this does not apply to the 90th percentile thresholds of $M$, for which, surprisingly, correlations are also positive over Uruguay. Thus, the entire distribution of $M$ becomes wider during El Niño episodes, with stronger precipitation as well as stronger evapotranspiration events. These results may be relevant in view of the importance of the La Plata Basin concerning agriculture and hydropower generation (e.g., Barros et al. 2006).

Positive correlations between MEI and daily mean and strong evapotranspiration event thresholds of $M$ as well as negative correlations between MEI and strong precipitation event thresholds in the Atacama Desert agree with earlier studies, which have found positive precipitation anomalies during La Niña episodes (Houston 2006a) as well as positive evapotranspiration anomalies during El Niño episodes (Houston 2006b).

\subsection{Impacts of ENSO cycles on clustering of moisture divergence}

Since no clear and significant impacts of ENSO on the clustering characteristics of strong precipitation events were found in the MERRA data, we will again focus on strong evapotranspiration events in the following section.

The distance matrix $\mathbf{L}$ (Fig. 6) obtained from the procedure described in Sect. 3 allows to identify times for which the spatial structures of LC resemble a specific characteristic pattern, indicated by low values of $L^{\mu \nu}$. Specifically, such low values of appear during El Niño conditions, which is supported by negative correlations between MEI and the row-wise mean of $\mathbf{L}$, i.e., $M L$ (Fig. 8). This result indicates that during El Niño periods, LC assumes a characteristic spatial pattern which exhibits lower variability in terms of mutual $L^{1}$-distances than for neutral and La Niña periods. The negative correlation between MEI and GC (Fig. 6) implies that during El Niño phases the spatial pattern of synchronized evapotranspiration extremes is characterized by decreased GC. This is interpreted as an overall tendency towards diminished spatial coherence of strong evapotranspiration events during El Niño conditions. Mean composites of LC for the different ENSO periods (Fig. 10) reveal 
that decreased values over the Amazon Basin are mainly responsible for this decline in GC.

Due to the interpretations of LC and SC (cf. Sect. 3), the results for $\mathrm{SC}$ are expected to be similar to those obtained for LC. Neglecting the influence of temporal lags, high values of LC computed from a CN based on ES should typically imply high values of SC as well, since the probability of link lengths in CNs typically decays roughly exponentially with the spatial distance between two sites (Radebach et al. 2013; Donges et al. 2009a). For the case of surface air temperatures, this is reflected by the emergence of densely connected structures in CNs during some time intervals, most remarkably during $\mathrm{El}$ Niño and La Niña periods (Tsonis and Swanson 2008; Radebach et al. 2013; Paluš and Hartman 2011).

Consistent with these expectations, the mean composites of SC (Fig. 11) indeed reveal a reduced average size of connected components of simultaneous evapotranspiration events over the Amazon Basin during warm ENSO phases as compared to neutral and cold periods. The implications are thus qualitatively the same as for LC, although the obtained patterns of SC exhibit less spatial variability and are in this sense less informative than those of LC. However, the consistency between the results of LC and SC provides further support of the drawn conclusions.

For strong events of evapotranspiration, we have found a clear block structure in the $L^{1}$-distance matrix $\mathbf{L}$ between the LC patterns for different time intervals (Fig. 6). This is expressed by a relatively high degree of similarity of LC patterns within the periods $1979-1998$ as well as 19922012 (with a mean $L^{1}$-distance of $2.45 \times 10^{7}$ ), while the $L^{1}$-distance of LC patterns between these two periods is relatively high (on average $2.57 \times 10^{7}$ ). The appearance of these two blocks in $\mathbf{L}$ may indicate a possible transition from one climate "state" to another one (characterized by a somewhat different typical clustering pattern of extreme evapotranspiration events) during the mid 1990s. In fact, another recent study Meehl et al. (2011) suggested a shift from El Niño dominated decades lasting until 1998 to a La Niña dominated period during the last 15 years, which is consistent with our finding. Specifically, the mean value of MEI for the time period from 1979 to 1998 is +0.54 , while the mean value of MEI for the years from 1992 to 2011 is +0.19 ( -0.12 for the years from 1998 to 2011). Recently, this shift was suggested as a possible explanation of the non-increasing global mean temperature in the last 15 years by the cooling effect of the Pacific Ocean during colder ENSO conditions (Kosaka and Xie 2013).

\subsection{Different types of El Niño events}

During the last years, several studies have reported evidence for a multi-phase nature of ENSO with at least two qualitatively different types of El Niño events (Ashok et al. 2007; Yeh et al. 2009; Hendon et al. 2009; Kim et al. 2011; Hu et al. 2012). However, we note that the assignment of El Niño events to these two subclasses is not fully consistent in the literature and partly depends on the chosen ENSO index. We suggest that a more detailed discrimination of ENSO phases allows deeper insights into the spatiotemporal organization of vertical moisture flux extremes. Here, we resolve the above results with respect to the two types of El Niño events and divide all El Niño events into the following two subclasses: Nino1, consisting of the particularly strong classical El Niño events in 1982, 1987, and 1997, and Nino2, consisting of the anomalous events in 1986, 1990/1991, 1993/1994, 2002, and 2004 (Hendon et al. 2009). We remark that in $\mathrm{Hu}$ et al. (2012), the El Niño event of 1987 is - in contrast to our assignment and (Yeh et al. 2009; Hendon et al. 2009; Kim et al. 2011) — taken to be an anomalous El Niño (i.e., Nino2) event. The classical El Niño (Nino1) is also referred to as eastern Pacific El Niño, while the anomalous El Niño (Nino2) is also called central Pacific El Niño, or El Niño Modoki (Ashok et al. 2007; Yeh et al. 2009). Nino2 is characterized by positive sea surface temperature (SST) anomalies in the central Pacific Ocean, but relatively cool SSTs to the east and west, while during (classical) Nino1 conditions, the SST maximum is located in the eastern Pacific Ocean. Furthermore, the two types of El Niño differ in their teleconnection patterns between the tropics and midlatitudes. The frequency of Nino2 episodes has increased during recent decades, possibly because of weakened tropical easterly winds (Ashok et al. 2007; Yeh et al. 2009). For a detailed analysis of the distinct impacts of Nino1 and Nino2 on precipitation over South America, we refer to Hill et al. (2009, 2011), Tedeschi et al. (2013), while Li et al. (2011) investigate the general impact on the climate of the Amazon Basin.

Constructing composites of means (Fig. 12) and 90th percentiles (Fig. 13) of moisture divergence as well as LC (Fig. 14) for these two types separately, we find that the impact of El Niño events on these three fields is mainly due to the classical type (Nino1), which shows much stronger deviations from neutral ENSO conditions than the anomalous type (Nino2). We thus infer that pronounced SST anomalies in the eastern Pacific ocean contribute much stronger to the described impacts of ENSO on moisture divergence than SST anomalies in the central Pacific ocean. This is consistent with results in Radebach et al. (2013), where distinctively different expressions in the properties of networks constructed from global surface air temperatures were found for the two El Niño types. In particular, the impact of El Niño events on GC was also mainly assigned to classical El Niño events in that study. 

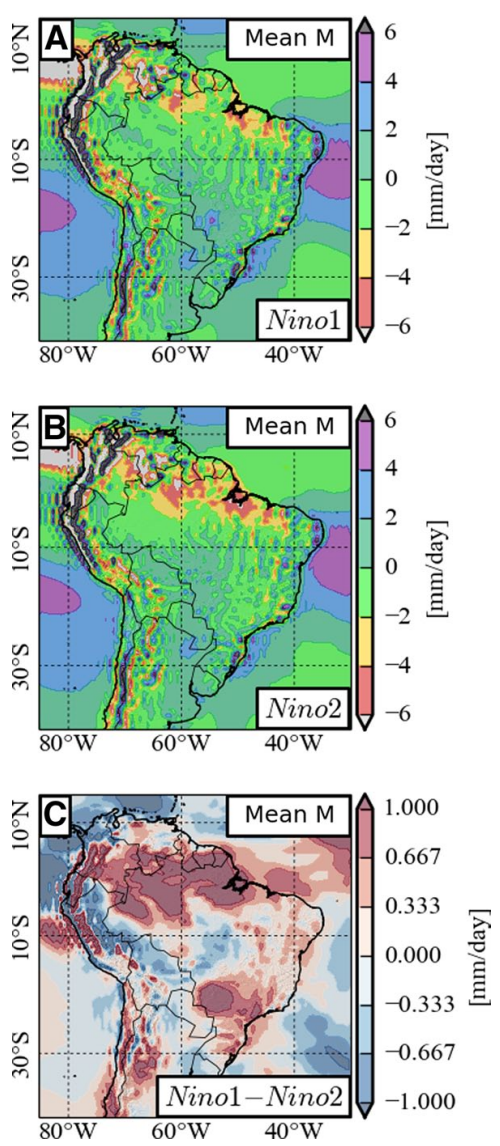

Fig. 12 Composites of mean daily moisture divergence $(M)$ for El Niño events of type Nino1 (a), Nino2 (b), and difference between Nino1 and Nino2 (c)

\section{Conclusion}

We have shown that magnitudes as well as spatial clustering of strong evapotranspiration events over South America are strongly affected by the phase of the ENSO. The strongest impacts of ENSO were found over the Amazon Basin, which is particularly important since this region is known to host globally relevant and particularly vulnerable ecosystems (Davidson et al. 2012). Specifically, the Amazon rainforest is believed to be one potential tipping element of the Earth's global climate system (Lenton et al. 2008).

We make the following key observations: (1) The magnitudes of moisture divergence respond positively to ENSO variability (indicating negative precipitation anomalies) in the Amazon Basin with highest values during El Niño periods. (2) The network-derived local clustering of extreme positive events of moisture divergence is reduced in a characteristic way during El Niño events in the Amazon Basin. This indicates reduced spatial coherence of synchronized extreme evapotranspiration events in this region. We find that the described dependence on ENSO variability is
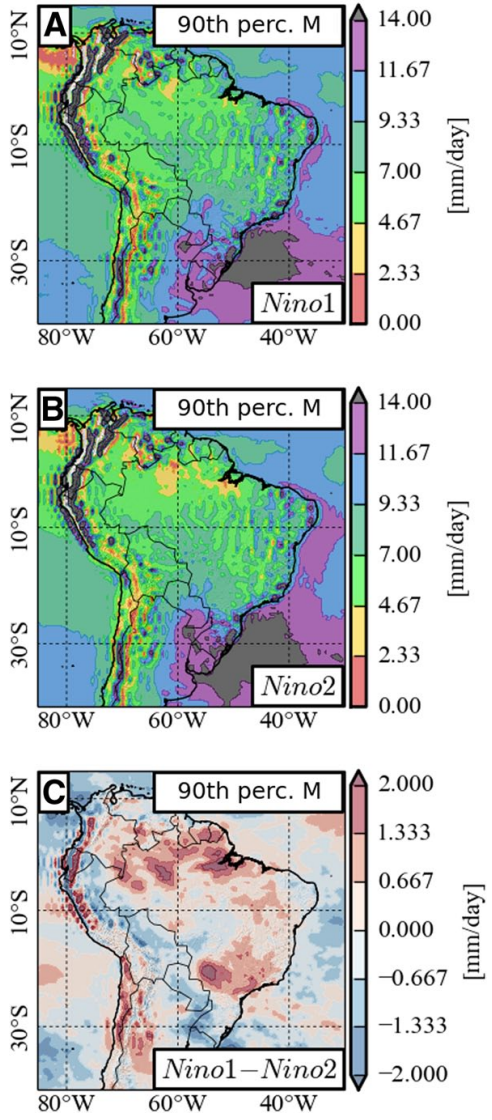

Fig. 13 Composites of 90th percentile thresholds of daily moisture divergence $(M)$ for El Niño events of type Nino1 (a), Nino2 (b), and difference between Nino1 and Nino2 (c)

mainly due to the three major (classical) El Niño events in 1982, 1987, and 1997, while all other events (in particular the anomalous Modoki events) play a minor role. A shift in ENSO activity during the late 1990's from warmer (El Niño) to cooler (La Niña) predominant conditions reported by others Meehl et al. (2011) is reflected by a shift in the pattern similarity of the CN's local clustering coefficients computed for extreme positive events of moisture divergence. (3) We find that our results obtained from complex network theory are consistent with, but more detailed than results obtained from a direct estimation of the spatial coherence of events.

We emphasize that these results were only found for the complex network analysis of extreme positive moisture divergence (i.e., evaotranspiration) events, and no corresponding significant results were found for extreme negative moisture divergence (i.e. precipitation) events.

From a conceptual perspective, our results underline the important role of complex network approaches as versatile tools for studying the spatiotemporal dynamics of the Earth's climate system on both global and regional scales. 

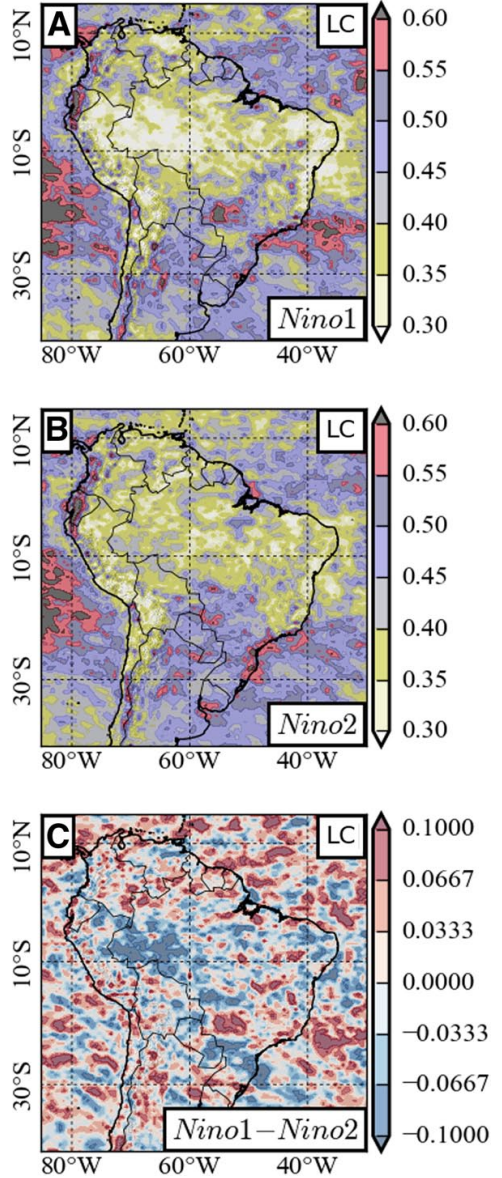

Fig. 14 Composites of LC for El Niño events of type Nino1 (a), Nino2 (b), and difference between Nino1 and Nino2 (c)

Besides providing information that cannot be obtained using classical methods originated in multivariate statistics (e.g., principal component analysis), the network parameters considered in this work are based on graph neighborhoods and can therefore be computed with moderate numerical efforts. In future work, we plan to analyze the impacts of La Niña episodes in more detail, as in this study we mainly focussed on the influence of El Niño episodes. As methodological refinement of the approach used in this study, we outline the explicit consideration of boundary effects on network properties (Rheinwalt et al. 2012) and heterogeneous distances between grid points on the sphere (Radebach et al. 2013) in future work.

Acknowledgments This paper was developed within the scope of the IRTG 1740/TRP 2011/50151-0, funded by the DFG/FAPESP. R.V.D. has been financially supported by the German Federal Ministry of Science and Education via the Young Investigators Group CoSy$\mathrm{CC}^{2}$ (Grant No. 01LN1306A). J.K. has been supported by the Government of the Russian Federation (Agreement No. 14.Z50.31.0033).

\section{References}

Ashok K, Behera SK, Rao SA, Weng H, Yamagata T (2007) Recent global-warming hiatus tied to equatorial Pacific surface cooling. J Geophys Res Ocean 112(C11007):1-27

Barros V, Clarke R, Dias P (2006) Climate Change in the La Plata Basin, Consejo Nacional de Investigaciones Científicas y Técnicas, $104 \mathrm{p}$

Berezin Y, Gozolchiani A, Guez O, Havlin S (2012) Stability of climate networks with time. Sci Rep 2:1-8

Boers N, Bookhagen B, Marwan N, Kurths J, Marengo J (2013) Complex networks identify spatial patterns of extreme rainfall events of the South American monsoon system. Geophys Res Lett 40(16):4386-4392. doi:10.1002/grl.50681

Bookhagen B, Strecker MR (2008) Orographic barriers, high-resolution TRMM rainfall, and relief variations along the eastern Andes. Geophys Res Lett 35(6):L06403

Bookhagen B, Strecker M (2010) Modern Andean rainfall variation during ENSO cycles and its impact on the Amazon drainage basin. In: Hoorn C, Wesselingh FP (eds) Amazonia: Landscape and Species Evolution: A look into the past. Wiley, Oxford, pp 223-243

Cazes-Boezio G, Robertson AW, Mechoso CR (2003) Seasonal dependence of ENSO teleconnections over South America and relationships with precipitation in Uruguay. J Clim 16:1159-1176. doi:10.1175/1520-0442(2003)16<1159:SDOETO>2.0.CO;2

Davidson Ea, de Araújo AC, Artaxo P, Balch JK, Brown IF, Bustamante MMC, Coe MT, DeFries RS, Keller M, Longo M, Munger JW, Schroeder W, Soares-Filho BS, Souza CM, Wofsy SC (2012) The Amazon basin in transition. Nature 481(7381):321-328. doi:10.1038/nature10717

Donges JF, Zou Y, Marwan N, Kurths J (2009a) Complex networks in climate dynamics. Eur Phys J Spec Top 174(1):157

Donges JF, Zou Y, Marwan N, Kurths J (2009b) The backbone of the climate network. Europhys Lett (EPL) 87(4):48007

Durkee JD, Mote TL, Shepherd JM (2009) The contribution of mesoscale convective complexes to rainfall across subtropical South America. J Clim 22(17):4590-4605

Durkee JD, Mote TL (2010) A climatology of warm-season mesoscale convective complexes in subtropical South America. Int J Climatol 30(3):418-431

Eltahir EaB, Bras RL (1993) Precipitation recycling in the Amazon basin. Q J R Meteorol Soc 120(518):861-880. doi:10.1002 /qj.49712051806

Garreaud R, Wallace J (1997) The diurnal march of convective cloudiness over the Americas. Mon Weather Rev 125(12):3157-3171

Hastenrath S, Heller L (1977) Dynamics of climatic hazards in Northeast Brazil. Q J R Meteorol Soc 103:77-92. doi:10.1002 /qj.49710343505

Hendon HH, Lim E, Wang G, Alves O, Hudson D (2009) Prospects for predicting two flavors of El Niño. Geophys Res Lett 36(19):L19713

Hill KJ, Taschetto AS, England MH (2009) South American rainfall impacts associated with inter-El Niño variations. Geophys Res Lett 36. doi:10.1029/2009GL040164

Hill KJ, Taschetto AS, England MH (2011) Sensitivity of South American summer rainfall to tropical Pacific Ocean SST anomalies. Geophys Res Lett 38. doi:10.1029/2010GL045571

Houston J (2006a) Variability of precipitation in the Atacama Desert: its causes and hydrological impact. Int J Climatol 26(15):21812198. doi: $10.1002 /$ joc

Houston J (2006b) Evaporation in the Atacama Desert: an empirical study of spatio-temporal variations and their causes. J Hydrol 330(3-4):402-412. doi:10.1016/j.jhydrol.2006.03.036 
Hu ZZ, Kumar A, Jha B, Wang W, Huang B, Huang B (2012) An analysis of warm pool and cold tongue El Niños: air-sea coupling processes, global influences, and recent trends. Clim Dyn 38(9-10):2017-2035

Kim W, Yeh SW, Kim JH, Kug JS, Kwon M (2011) The unique 2009/2010 El Niño event: a fast phase transition of warm pool El Niño to La Niña. Geophys Res Lett 38(15):L15809

Kosaka Y, Xie SP (2013) Recent global-warming hiatus tied to equatorial Pacific surface cooling. Nature 501(7467):403-407. doi:10.1038/nature12534

Lean J, Warrilow D (1989) Simulation of the regional climatic impact of Amazon deforestation. Nature 342:411-413

Lenton TM, Held H, Kriegler E, Hall JW, Lucht W, Rahmstorf S, Schellnhuber HJ (2008) Tipping elements in the Earth's climate system. Proc Nat Acad Sci 105(6):1786-1793. doi:10.1073/p nas.0705414105

Li W, Zhang P, Ye J, Li L (2011) Impact of two different types of El Nino events on the Amazon climate and ecosystem productivity. J Plant Ecol 4:91-99. doi:10.1093/jpe/rtq039

Ludescher J, Gozolchiani A, Bogachev MI, Bunde A, Havlin S, Schellnhuber HJ (2013) Improved El Niño forecasting by cooperativity detection. Proc Natl Acad Sci 110(29):11742-11745

Malik N, Marwan N, Kurths J (2010) Spatial structures and directionalities in monsoonal precipitation over South Asia. Nonlinear Process Geophys 17(5):371-381

Malik N, Bookhagen B, Marwan N, Kurths J (2012) Analysis of spatial and temporal extreme monsoonal rainfall over South Asia using complex networks. Clim Dyn 39(3):971-987. doi:10.1007/ s00382-011-1156-4

Marengo JA, Nobre C, Tomasella J, Oyama M, Sampaio de Oliveira G, de Oliveira R, Camargo H, Alves L, Brown F (2008) The drought of Amazonia in 2005. J Clim 21(3):495-516. doi:10.11 75/2007JCLI1600.1

Meehl GA, Arblaster JM, Fasullo JT, Hu A, Trenberth KE (2011) Model-based evidence of deep-ocean heat uptake during surfacetemperature hiatus periods. Nat Clim Change 1(7):360-364. doi :10.1038/nclimate1229.http://www.nature.com/nclimate/journal/ v1/n7/abs/nclimate1229.html\#supplementary-information

Paluš M, Hartman D (2011) Discerning connectivity from dynamics in climate networks. Nonlinear Process Geophys 18:751-763. doi :10.5194/npg-18-751-2011

Quiroga RQ, Kreuz T, Grassberger P (2002) Event synchronization: a simple and fast method to measure synchronicity and time delay patterns. Phys Rev E 66(4):41904

Radebach A, Donner R, Runge J, Donges J, Kurths J (2013) Disentangling different types of El Niño episodes by evolving climate network analysis. Phys Rev E 88:052807. doi:10.1103/PhysR evE.88.052807

Rasmusson E, Carpenter T (1982) Variations in tropical sea surface temperature and surface wind fields associated with the Southern Oscillation/El Niño. Mon Weather Rev 110:354-384. doi:10.1175/1520-0493(1982)110<0354:VITSST>2.0.CO;2
Rheinwalt A, Marwan N, Kurths J, Werner P, Gerstengarbe FW (2012) Boundary effects in network measures of spatially embedded networks. Europhys Lett (EPL) 100(2):28002

Rienecker MM, Suarez MJ, Gelaro R, Todling R, Bacmeister J, Liu E, Bosilovich MG, Schubert SD, Takacs L, Kim GK, Bloom S, Chen J, Collins D, Conaty A, Da Silva A, Gu W, Joiner J, Koster RD, Lucchesi R, Molod A, Owens T, Pawson S, Pegion P, Redder CR, Reichle R, Robertson FR, Ruddick AG, Sienkiewicz M, Woollen J (2011) MERRA: NASA's modern-era retrospective analysis for research and applications. J Clim 24:3624-3648. doi:10.1175/JCLI-D-11-00015.1

Ropelewski C, Halpert M (1987) Global and regional scale precipitation patterns associated with the El Niño/Southern Oscillation. Mon Weather Rev 115(8):1606-1626

Shukla J, Nobre C, Sellers P (1990) Amazon deforestation and climate change. Science 247:1322-1325

Steinhaeuser K, Ganguly AR, Chawla NV (2012) Multivariate and multiscale dependence in the global climate system revealed through complex networks. Clim Dyn 39(3-4):889-895. doi:10.1007/s00382-011-1135-9

Steinhaeuser K, Tsonis AA (2014) A climate model intercomparison at the dynamics level. Clim Dyn 42(5-6):1665-1670

Tedeschi RG, Cavalcanti IFA, Grimm AM (2013) Influences of two types of ENSO on South American precipitation. Int J Climatol 33:1382-1400. doi:10.1002/joc.3519

Trenberth KE (1997) The definition of El Nino. Bull Am Meteorol Soc 78:2771-2777. doi:10.1175/1520-0477(1997)078<2771:TDOEN $\mathrm{O}>2.0 . \mathrm{CO} ; 2$

Trenberth K, Stepaniak D (2001) Indices of El Niño evolution. J Clim 14:1697-1701. doi:10.1175/1520-0442(2001)014<1697:LIOEN $\mathrm{O}>2.0 . \mathrm{CO} ; 2$

Tsonis AA, Roebber PJ (2004) The architecture of the climate network. Phys A 333:497-504

Tsonis A, Swanson K, Kravtsov S (2007) A new dynamical mechanism for major climate shifts. Geophys Res Lett 34:L13705. doi: 10.1029/2007GL030288

Tsonis A, Swanson K (2008) Topology and predictability of El Niño and La Niña networks. Phys Rev Lett 100(22):228502. doi:10.11 03/PhysRevLett.100.228502

Wolter K, Timlin MS (1998) Measuring the strength of ENSO events-how does 1997/98 rank? Weather 53:315-324

Wolter K, Timlin MS (1993) Proceedings of the 17th climate diagnostics workshop, Norman, OK, NOAA/NMC/CAC, NSSL, Oklahoma Clim. Survey, CIMMS and the School of Meteor., University of Oklahoma, pp 52-57

Yamasaki K, Gozolchiani A, Havlin S (2008) Climate networks around the globe are significantly affected by El Nino. Phys Rev Lett 100(22):228501

Yeh SW, Kug JS, Dewitte B, Kwon MH, Kirtman BP, Jin FF (2009) El Niño in a changing climate. Nature 461:511-514. doi:10.1038/ nature 08316 